\title{
Intestinal motility after ileal pouch-anal anastomosis
}

\author{
JACQUES HEPPELL, MD, FRCSC
}

\begin{abstract}
Colectomy, mucosal proctectomy and ileal pouch-anal anastomosis, has become the procedure of choice for carefully selected patients with ulcerative colitis requiring surgery. Pathophysiological studies after the operation have led to a better understanding of the mechanisms of continence and to the development of new technology to study anorectal function. Manometric studies of the anal sphincter, ileal pouch and distal ileum have shown that the operation alters the mechanisms of continence. The maximal tolerable volume of distension of an ileal pouch often approximates that of a normal rectum and yet the functional outcome may differ from a well functioning ileorectal anastomosis. Many other factors influence the result of the operation. The influence of the pattern of motility of the proximal and distal small bowel has been evaluated. The ileal pouch accommodation to distension has been correlated to clinical outcome. Scintigraphic techniques were designed to study the relationship between motility, filling and emptying of the ileal reservoirs. Measures designed to slow intestinal transit, increase absorption and reduce stool output are under investigation. Can J Gastroenterol 1990;4(7):432-435
\end{abstract}

Key Words: Intestinal motility, Ulcerative colitis

\section{La motilité intestinale après anastomose iléo-anale avec réservoir iléal}

RESUME: La colectomie avec mucosectomie rectale et anastomose iléo-anale avec réservoir iléal est une intervention de choix pour les patients atteints de colite ulcéreuse qui doivent être opérés. Les études physiopathologiques après cette intervention ont permis de mieux comprendre les mécanismes de la continence et de développer de nouvelles technologies pour en étudier la fonction. L'étude manométrique des sphincters de l'anus, du réservoir iléal et de l'iléon distal a démontré que les mécanismes de continence sont modifiés après l'opération. Bien que la capacité du réservoir mesurée selon le volume maximal tolérable de distension est parfois bien similaire à celui d'un rectum normal, le résultat peut être différent d'une anastomose iléo-rectale. L'influence de la motilité du grêle et l'accommodation du réservoir à la distension ont été évaluées et reliées au résultat fonctionnel. Des techniques scintigraphiques permettent d'étudier la relation entre la motilité, le remplissage et l'évacuation d'un réservoir iléal. Afin d'améliorer les résultats, des études cliniques sont en cours pour trouver les moyens de ralentir le transit intestinal, augmenter l'absorption et réduire le volume du bol fecal.

Département de Chirurgie, Université de Montréal, Hôtel-Dieu de Montréal, Montréal, Québec

Correspondence and reprints: Dr J Heppell, Associate Professor of Surgery, Département de Chirurgie, Université de Montréal, Hôtel-Dieu de Montréal, 3840 St-Urbain, Montréal, Québec H2W IT8. Telephone (514) 843-2611 ext 4945, Fax (514) 843-2704
T OTAL COLECTOMY, MUCOSAL proctectomy and endorectal ileal pull-through, was first described in 1948 by Ravitch (1) for the treatment of benign conditions such as ulcerative colitis and familial polyposis coli. This operation enjoyed only periodic popularity because of numerous post. operative problems, primarily as a result of infection and incontinence, which plagued the procedure. Historical perspectives on the ileoanal anas. tomosis are well reviewed by Stryker and Dozois (2) and Pemberton et al (3). Careful clinical observations and knowledge of the normal physiology of fecal continence inevitably led to fur. ther refinements. Gaston (4) in 1948 showed that continence requires two distinct mechanisms. Reservoir continence depends on plastic adaptation of the smooth muscle of the colon and rectum. When this adaptation reaches its limit, sphincteric continence comes into play. Formal laboratory investigations of ileal reservoirs constructed to replace the rectum were reported by Valiente and Bacon (5) in 1955. Karlan and colleagues (6) in 1959 noted that dogs with an ileal reservoir fashioned proximal to an ileoanal anastomosis had a greater degree of continence than dogs without a reservoir. In 1969, Kock (7) described an internal reservoir and later showed that its presence was consistent with normal intestinal function (8).

The favorable clinical report and technical considerations of Martin etal $(9,10)$ in performing total colectomy and Soave endorectal anastomosis for 
ulcerative colitis revived interest in the ileoanal anastomosis. The clinical outcome after straight ileoanal anastomosis in adults was not as good as in the pediatric group: the overall adult failure rate was $33 \%$ (11).

In 1978, an operation in which an ileal reservoir was constructed proximal to an ileoanal anastomosis was described in humans (9). Since then, various types of ileal reservoirs have been described $(10,11)$.

Many investigators have studied the mechanisms by which continence can be maintained in patients following these operations. The purpose of this article is to review some aspects of intestinal motility after ileal pouch-anal anastomosis and their relation to clinical outcome.

\section{MECHANISMS OF FECAL CONTINENCE IN HEALTH}

The main functions of the rectum and anus are to preserve fecal continence so that one can defer defecation voluntarily, distinguish solids, liquids and gases, and maintain nocturnal control. The physiology of continence is complex and the mechanisms involve both conscious and unconscious components. An understanding of the normal physiology of continence provides a background against which the effect of total colectomy, mucosal proctectomy and ileoanal anastomosis must be compared (15).

To achieve continence, several physiologic mechanisms interact: the resistance of the anal sphincters, anorectal angulation, rectosphincteric reflexes, the reservoir function of the distal bowel, sensory mechanisms, the volume and consistency of stools and the effect of intestinal propulsion. Anal continence results from a balance between the consistency and rate of delivery of rectal contents and the competence of the anorectal structures together with suppression of the urge to defecate.

\section{ALTERED PHYSIOLOGY AFTER THE OPERATION}

Anal sphincters: The resting and maximal squeeze anal canal pressures after mucosal stripping and endorectal ileoanal anastomosis are usually preserved compared to a control group (16-19). However, Becker (20) has shown reduced resting anal canal pressure postoperatively. Anal retraction during mucosal stripping probably contributes to this finding. Resting anal sphincter pressures were shown to be uniformly reduced in the incontinent group by O'Connell et al (18). Most episodes of incontinence occur during the night, when anal sphincter pressures are lessened (unpublished data). Electromyographic studies have been used by Stryker et al (21) to detect subtle damage to the external anal sphincter or its nerve supply during ileoanal anastomosis in some patients. Using a microtransducer technique, Lindquist (22) has shown that endoanal mucosal proctectomy has an adverse effect on the sphincter mechanism manifested by a temporary reduction of the maximal squeeze pressure (at 12 months) and the likely permanent impairment of resting tone. However, no correlation between resting pressure and continence was found in that study. A low resting pressure was associated with a high frequency of bowel movements and poor deferral (less than 30 mins).

To facilitate the mucosectomy and to reduce the risk of remaining rectal mucosa, the rectal wall is often divided close to the levators (23). The intramural neural pathways mediating the rectoanal inhibitory reflex are divided. Continence after ileoanal anastomosis is not significantly impaired by the absence of this reflex $(17,24,25)$. The ability to distinguish stool from flatus seems to be independent of this reflex. Moreover, Grant et al (25) have shown that the clinical results and manometric findings after restorative proctocolectomy are similar with long and short rectal cuffs. Whether or not the mucosal sensory zone proximal to the dentate line should be preserved to enhance sensory discrimination of enteric content remains controversial.

The neorectal angle: The puborectalis muscle normally pulls the anorectal junction toward the pubis, thus creating a 'flap valve' mechanism which contributes to continence in situations where a sudden increase in intra-abdominal pressure exceeds the intraluminal anal canal pressure ( $\mathrm{eg}$, the Valsalva maneuvre). It was postulated that since all of the dissection is performed intrarectally, the puborectalis sling of the levator ani complex would remain intact. A completely open anoneorectal angle may be related to postoperative leakage. In topographic assessments of ileoanal reservoirs, Lindquist et al (26) were not able to confirm this assumption. Using lateral neorectal scintigraphic scanning, O'Connell et al (27) have shown that the anal-pouch angle after the operation differs little from the anorectal angle in health.

\section{ILEAL RESERVOIR}

The rationale for using an ileal reservoir is to attempt to provide an adequate replacement for the rectum by constructing a low pressure, compliant, less propulsive reservoir which can evacuate spontaneously at a reasonable threshold volume. Using a soft latex balloon to distend the distal bowel the present author found that the mean tolerable volume of neorectal distension 11 months after ileostomy closure in a group of 12 patients with straight ileoanal anastomosis was $248 \pm 31 \mathrm{~mL}$ versus $406 \pm 26 \mathrm{~mL}$ in 10 healthy controls (16). He also observed that the greater the maximal tolerable volume of neorectal distension, the smaller the number of bowel movements per day $(r=0.9 ; \mathrm{P}<0.001)$. From clinical observations, Taylor et al (28) have noted that the greatest benefit of the reservoir may be in the early months after stomal closure, at which time stool frequency was significantly reduced. Ileal capacity and compliance increase progressively during the postoperative period $(19,29)$. Indeed, the maximum capacity and distensibility of the ileal 'J' pouch have been found to approximate that of a normal rectum $(17,30)$.

The motility of the terminal ileum after straight ileoanal anastomosis was evaluated by inserting a perfused catheter above the anal sphincters transanally after an overnight fast. Two types of pressure waves were found in 
the ileum: small amplitude waves (14 $\mathrm{cmH}_{2} \mathrm{O}$ ) of short duration and large amplitude waves (mean $66 \mathrm{cmH}_{2} \mathrm{O}$ ) of longer duration (31). These large waves corresponded to the classic type IV waves' initially described by Code et al (32) in 1957. Clearly, the urge to defecate occurred concomitant with these large pressure waves and leakage occurred as the peak amplitude of these waves exceeded the resistance of the anal sphincters. The pattern of ileal motility contributed to clinical results in these patients. Construction of an ileal reservoir increased the volume accommodated within the terminal ileum and reduced the mean amplitude of the ileal pressure waves (24). In the normal rectum only infrequent and low amplitude contractions are detected, even with distension to maximum capacity (16). Luminal distension has been shown to stimulate large pressure waves in the ileum. Rabau et al (33) found that a distending volume of only $30 \mathrm{~mL}$ was necessary to trigger these contractions in the ileum proximal to a Brooke ileostomy, whereas $322 \mathrm{~mL}$ was required to induce these contractions in the 'S' pouch. The frequency and amplitude of the large pressure waves increase with time during fasting as the ileal pouch fills $(17,31)$. These waves are abolished by evacuation of stool. Stryker et al (17) have shown that the interval of onset of the large pressure waves after evacuation was significantly related to stool frequency. O'Connell et al (30) demonstrated that the volume of ileal distension at which the large pressure waves appear ('threshold volume') is an important determinant of stool frequency. The threshold volume is a function of both the capacity and the compliance of the ileal reservoir. In patients with active colitis, Rao et al (34) have shown that the distal bowel reacts to intraluminal contents by generating vigorous contractions that challenge the continence mechanism, and cause frequent, urgent and painful defecation.

In an experimental assessment of pelvic ileal reservoir function compared to that of a normal rectum, Cranley et al (35) found that while satisfactory continence could be achieved by an ileal reservoir, the ability of normal rectum to evacuate completely was disturbed. Similarly, using a semisolid radionuclide enema to assess ileal pouch emptying quantitatively, the author found that the ileal pouch emptied less efficiently than a normal rectum (36). In contrast, others have found that the ileal 'J' pouch empties as well as the healthy rectum $(17,37)$; but no overall differences were found between the efficiency of pouch evacuation and frequency of stools $(36,37)$. Moreover, pouchitis may not always be related to poor emptying (3638).

Quigley et al (39) observed large amplitude pressure waves in the distal 20 to $30 \mathrm{~cm}$ of healthy ileum. After the operation, these waves were also detected up to $125 \mathrm{~cm}$ proximal to the ileal pouch by Stryker et al (40). The migrating motor complexes found in the jejunoileum during fasting remain unchanged as shown by Stryker et al (40) and Chaussade et al (41). These investigators also observed the presence of discrete clustered contractions in the proximal small bowel previously described in partial small intestinal obstruction by Summers et al (43). The relationship between jejunoileal motility and function of the ileal reservoir remains unclear. The rate of delivery of stools into the neorectum may facilitate accommodation to distension.

\section{STOOL OUTPUT}

After straight ileoanal anastomosis, the author found a mean total daily stool volume of $598 \pm 60 \mathrm{~g}$, similar to that after Brooke ileostomy or after a well functioning Kock pouch (16). When the normal absorptive function of the colon is present, a mean volume of $150 \mathrm{~g}$ is expected. This increase in stool volume may explain the increased frequency of evacuation after operation. After ileal pouch-anal anastomosis, O'Connell et al (30) found that the volume of stool passed per day is the most important determinant of stool frequency. In patients with ileostomy the output depends on the amount of fibre in the diet. Loperamide was reported by Emblem et al (43) to reduce fecal output significantly after ileoanal anastomosis, probably by increasing transit time, which promoted absorp. tion of water and electrolytes. Recently, Soper et al (44) showed that infusion of oleic acid into the ileal pouch slowed gastric emptying and small bowel transit and delayed defeca. tion. An 'ileal brake' on gastrointes. tinal transit is functional after ileal pouch-anal anastomosis.

In conclusion, measures that slow intestinal transit, increase absorption and reduce stool output would be clinically beneficial. Moreover, new tech. nology will aid understanding of the pathophysiology of adaptation following these operations and improve results (45). This review of several aspects of intestinal motility after ileal pouch-anal anastomosis demonstrates how continence can be restored surgically based on an expanding knowledge of applied gastrointestinal physiology gained in the laboratory by dedicated investigators (46).

ACKNOWLEDGEMENTS: The author thanks Mrs Linda Gagné for her secretarial assistance.

\section{REFERENCES}

1. Ravitch MM. Anal ileostomy with sphincter preservation in patients requiring total colectomy for benign conditions. Surgery 1948;24:170-87.

2. Stryker SJ, Dozois RR. The ileoanal anastomosis: Historical perspectives. In: Dozois RR, ed. Alternatives to Conventional Ileostomy. Chicago: Year Book Medical Publishers, 1985:255-65

3. Pemberton JH, Heppell J, Beart RW, Dozois RR, Telander RL. Endorectal ileoanal anastomosis. Surg Gynecol Obstet 1982;155:417-24.

4. Gaston EA. The physiology of faecal continence. Surg Gynecol Obstet 1948;87:280-90,

5. Valiente MA, Bacon HE. Construction of a pouch using 'pantaloon' technique for pull-through of ileum following total colectomy. Am J Surg 1955;90:742-9.

6. Karlan M, McPherson RC, Watman RN. An experimental evaluation of faecal continence - Sphincter and reservoir in the dog. Surg Gynecol Obstet 1959;108:469-75.

7. Kock NG. Intra-abdominal 'reservoir' 
in patients with permanent ileostomy. Arch Surg 1969;99:223-31.

8. Kock NG, Darle N, Kewenter J, et al. The quality of life after proctocolectomy and ileostomy. Dis Colon Rectum 1974;17:287-92

9. Martin LW, LeCoultre C, Schubert WR. Total colectomy and mucosal proctectomy with preservation of continence in ulcerative colitis. Ann Surg 1977;186:477-9.

10. Martin LW, LeCoultre C. Technical considerations in performing total colectomy and Soave endorectal anastomosis for ulcerative colitis. J Pediatr Surg 1978;13:762-4.

11. Beart RW, Dozois RR, Kelly KA. Ileoanal anastomosis in the adult. Surg Gynecol Obstet 1982;154:826-9.

12. Parks AG, Nicholls RJ. Proctocolectomy without ileostomy for ulcerative colitis. Br J Surg 1978;3:85-8.

13. Fonkalsrud EW. Endorectal ileal pullthrough with lateral ileal reservoir for benign colorectal disease. Ann Surg 1981;194:761-6.

14. Utsunomiya J, Iwama I, Imajo M, et al. Total colectomy, mucosal proctectomy and ileoanal anastomosis. Dis Colon Rectum 1980;23:459-66.

15. Heppell J, Devroede G, Arhan P. Mechanisms of fecal continence in alternatives to conventional ileostomy. In: Dozois RR, ed. Chicago: Year Book Medical Publishers, 1985:274-89.

16. Heppell J, Kelly KA, Phillips SF, et al. Physiologic aspects of continence after mucosal proctectomy and endorectal ileoanal anastomosis. Ann Surg 1982;195:435-43.

17. Stryker SJ, Kelly KA, Phillips SF, Dozois RR, Beart RW. Anal and neorectal function after ileal pouchanal anastomosis. Ann Surg 1986;203:55-61

18. O'Connell PR, Stryker SJ, Metcalf AM, Pemberton JH. Anal canal pressure and motility after ileoanal anastomosis. Surg Gynecol Obstet 1988;166:47-54.

19. Neal DE, Williams NS, Johnston D Rectal, bladder and sexual function with and without a pelvic reservoir. Br J Surg 1982;69:599-601.

20. Becker JM. Anal sphincter function after colectomy, mucosal proctectomy, and endorectal ileoanal pull-through. Arch Surg 1984;119:526-31.

21. Stryker S, Daube JR, Kelly KA, et al. Anal sphincter electromyography after colectomy, mucosal rectectomy, and ileoanal anastomosis. Arch Surg 1985;120:713-6.

22. Lindquist K. Anal manometry with micro transducer technique before and after restorative proctocolectomy. Dis Colon Rectum 1990;33:91-8.

23. Ballantyne GH, Pemberton JH, Beart RW, Wolf BG, Dozois RR. Ileal J pouch-anal anastomosis: Current technique. Dis Colon Rectum 1985;28:197. 202.

24. Taylor BM, Cranley B, Kelly KA, Phillips SF, Beart RW, Dozois RR. A clinico-physiological comparison of ileal pouch-anal and straight ileo-anal anastomosis. Ann Surg 1983;198:462. 9.

25. Grant, D, Cohen Z, McHugh S, et al. Restorative proctocolectomy. Clinical results and manometric findings with long and short rectal cuffs. Dis Colon Rectum 1986;29:27-32.

26. Lindquist K, Liljequist L, Sellberg B. The topography of ileo-anal reservoirs in relation to evacuation patterns and clinical functions. Acta Chir Scand 1984;150:573-9.

27. O'Connell PR, Pemberton JH, Kelly $\mathrm{KA}$. The function of the ileal J-pouch and its relation to clinical outcome after ileal pouch-anal anastomosis. World J Surg 1987;11:731-41.

28. Taylor BM, Beart RW, Dozois RR, et al. Straight ileoanal anastomosis versus ileal-pouch anal anastomosis after colectomy and mucosal proctectomy. Arch Surg 1983;118:696-701.

29. Schraut WH, Block GE. Ileo anal anastomosis with proximal ileal reservoir: An experimental study. Surgery 1982;91:275-81.

30. O'Connell PR, Pemberton JH, Brown ML, Kelly KA. Determinants of stool frequency after ileal pouch-anal anastomosis. Am J Surg 1987;153:157-64.

31. Heppell J, Pemberton JH, Kelly KA, Phillips SF. Ileal motility after endorectal ileo-anal anastomosis. Surg Gastroenterol 1982;1:124-7.

32. Code CF, Rogers AG, Schlegal ], Hightower NC, Bargen JA. Motility patterns in the terminal ileum: Studies on two patients with ulcerative colitis and ileal stomas. Gastroenterology 1957;32:651-6.

33. Rabau MY, Percy JP, Parks AG. Ileal pelvic reservoir: A correlation between motor patterns and clinical behaviour. Br J Surg 1982;69:391-5.

34. Rao SSC, Read NW, Stobart IAH, Haynes WG, Benjamin S, Holdsworth
CD. Anorectal contractility under basal conditions and during rectal infusion of saline in ulcerative colitis. Gut 1988;29:769-77.

35. Cranley B, McKelvey STD. Ileal reservoirs: An experimental study of the motility in the Kock and triplicated pelvic ileal pouches. J Surg Res 1983;34:279-85

36. Heppell J, Belliveau P, Taillefer R, Dubé S, Derbekyan V. Quantitative assessment of pelvic ileal reservoir with a semisolid radionuclide enema. Dis Colon Rectum 1987;30:81-5.

37. O'Connell PR, Kelly KA, Brown ML. Scintigraphic assessment of neorectal motor function. J Nucl Med 1986;27:460-3.

38. O'Connell PR, Rankin DR, Weiland LH, Kelly KA. Enteric bacteriology, absorption, morphology and emptying after ileal pouch-anal anastomosis. $\mathrm{Br}$ J Surg 1986;73:909-14.

39. Quigley EM, Borody TJ, Phillips S, et al. Motility of the terminal ileum and ileo-caecal sphincter in healthy humans. Gastroenterology 1984:87:857-66.

40. Stryker SJ, Borody TJ, Phillips SF, Kelly KA, Dozois RR, Beart RW. Motility of the small intestine after proctocolectomy and ileal pouch-anal anastomosis. Ann Surg 1985;201: 351-6.

41. Chaussade S, Merite F, Hautefeuille M, Valleur P, Hautefeuille P, Couturier D. Motility of the jejunum after proctocolectomy and ileal pouch anastomosis. Gut 1989;30:371-5.

42. Summers W, Anuras S, Green J. Jejunal manometry patterns in health, partial obstruction and pseudo obstruction. Gastroenterology 1983;85:1290. 300.

43. Emblem R, Stien R, Morkrid L. The effect of loperamide on bowel habits and anal sphincter function in patients with ileo-anal anastomosis. Scand J Gastroenterol 1989;24:1019-24.

44. Soper NJ, Chapman NJ, Kelly KA, Brown ML, Phillips SF, Go VLW. The 'Ileal brake' after ileal pouch-anal anastomosis. Gastroenterology 1990;98:111-6.

45. Williams NS. Impact of new technology on anorectal disorders. Br J Surg 1987;74:235-6.

46. Pemberton JH, Kelly KA. Achieving enteric continence: Principles and applications. Mayo Clin Proc 1986;61:586-99. 


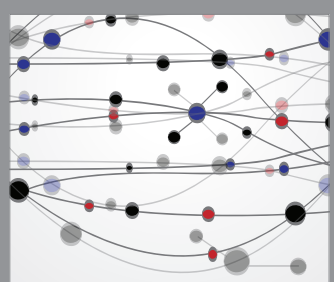

The Scientific World Journal
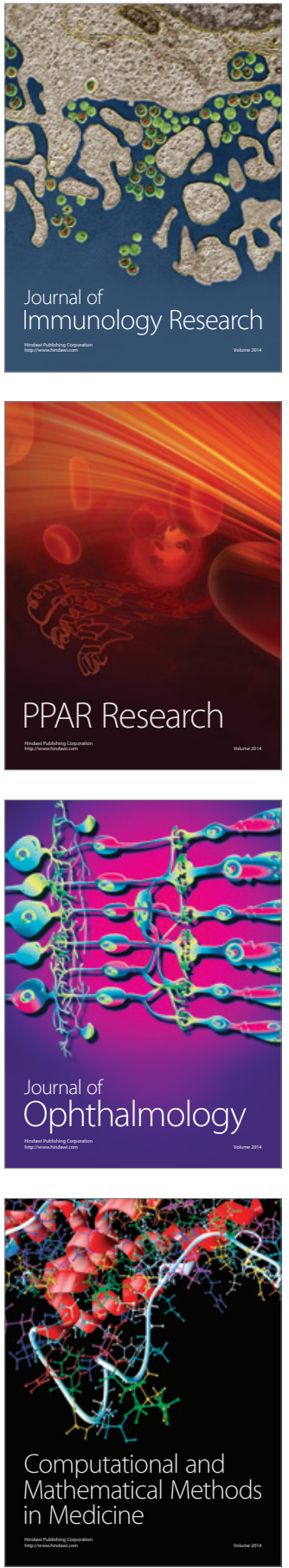

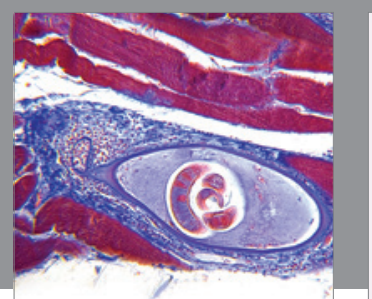

Gastroenterology Research and Practice

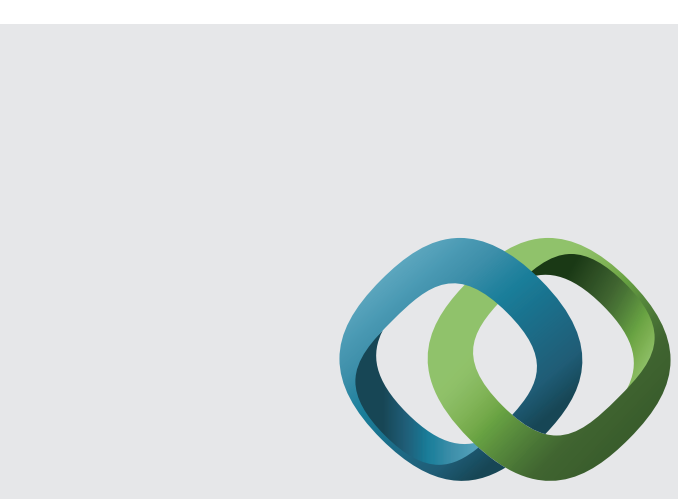

\section{Hindawi}

Submit your manuscripts at

http://www.hindawi.com
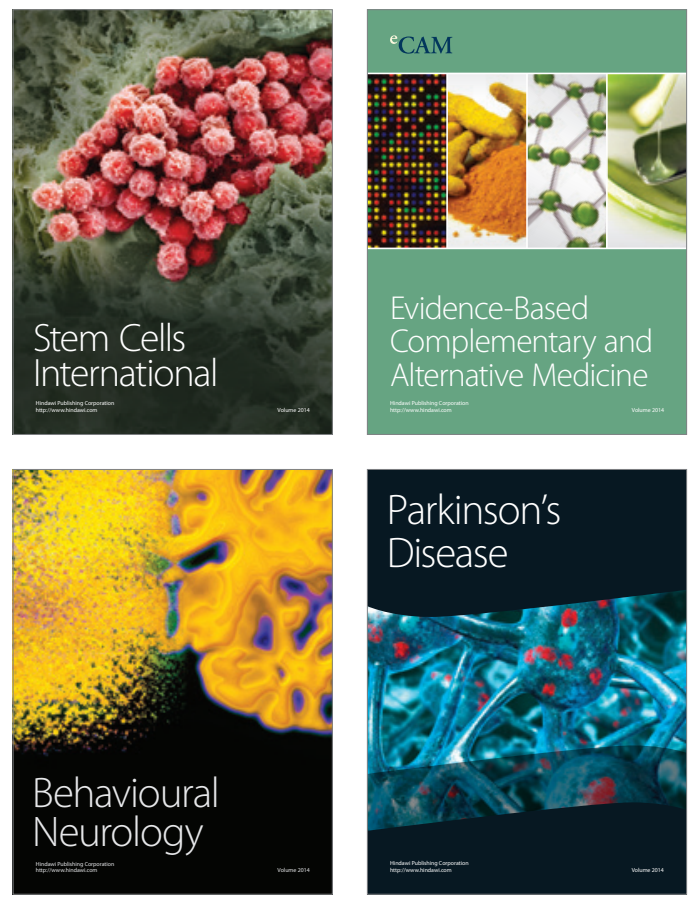
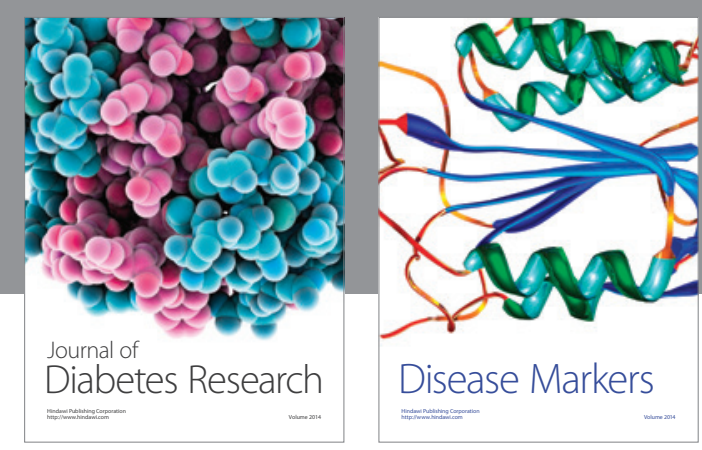

Disease Markers
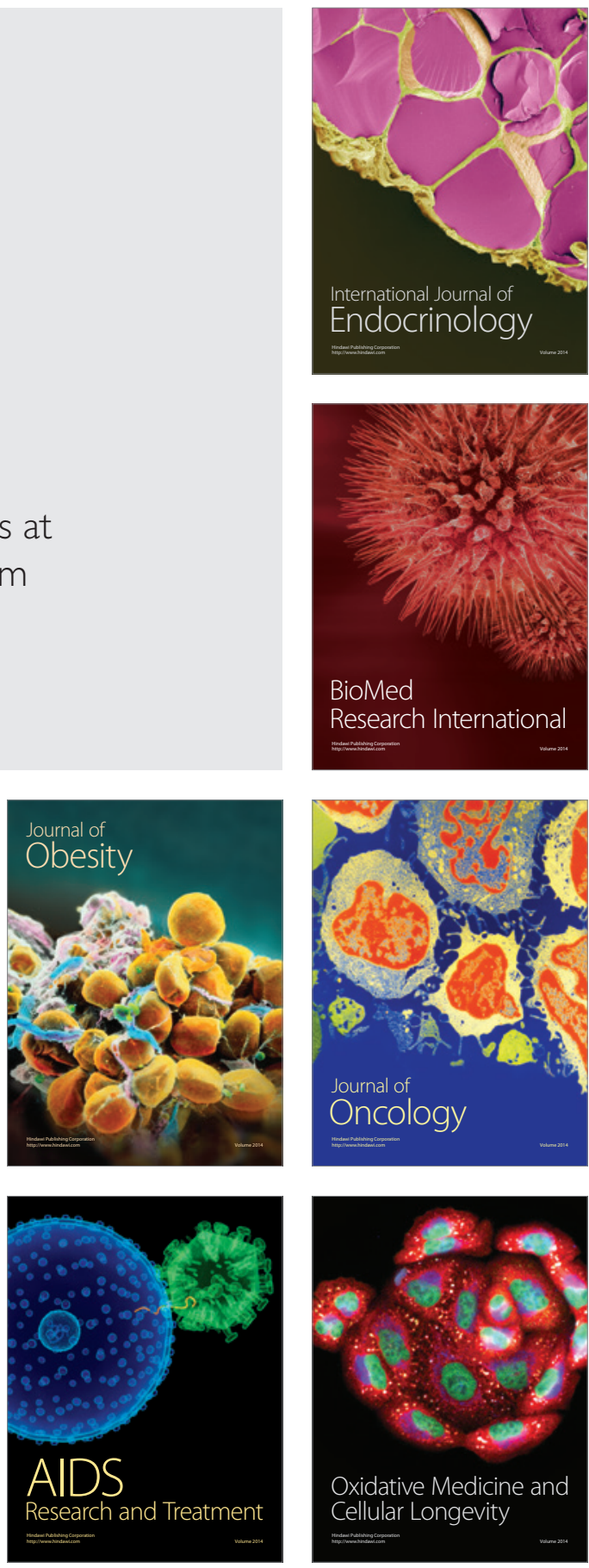